\title{
Role of Training in Determining the Employee Corporate Behavior with Respect to Organizational Productivity: Developing and Proposing a Conceptual Model
}

\author{
Mohsin Nadeem \\ Fauji Foundation Institute of Engineering and Management Sciences (FUIEMS) \\ Islamabad, Pakistan \\ E-mail: Mohsin.nadeem@live.com
}

\begin{abstract}
In this research, I have proposed a model which focuses on the impact of effectual corporate behavior on organizational productivity. I have examined the relationship between key variables of corporate behavior i.e. employee commitment, employee motivation and job satisfaction on organizational productivity with assistance of training. Previous literature and my research reveal a positive correlation between the effective corporate behavior and productivity but with the aid of training and by controlling unobserved heterogeneity and potential endogeneity.
\end{abstract}

Keywords: Employee commitment, Employee motivation, Job satisfaction, Organizational productivity, Unobserved Heterogeneity, Potential endogeneity

\section{Introduction}

The primary motive of every business organization is to earn profits. Every decision from planning to staffing, are taken for long term sustainability of organization. Human resource is the most important and vital factor of economic development. Better education, improved skills, and provision of healthy atmosphere will result in proper and most efficient use of resources, resulting in economic growth. Nowadays, due to cutthroat competition in corporate world, an employee needs to be skillful and professionally strong in order to survive. Only satisfied, committed and motivated employees are meeting the level of expectations, expanding their skill horizon, through training which holds the key to success.

\subsection{Employee Motivation and Productivity}

The success of every business organization depends fundamentally on the motivation of the employees. In basic terms, motivation is an inner drive that compels behavior. Employee motivation begins with understanding that within every human being, there is an inner drive that compels behavior. (Incentivequotes, 2010).In other words, everyone has motivation. Human resources are essential to the triumph, efficiency and performance of any company. Motivation provides an environment where employee optimal performance is possible. Perhaps the most significant impact of increased employee motivation is that of increased productivity. (Ezinearticle, 2010).

\subsection{Job Satisfaction and Productivity}

Job satisfaction describes how content an individual is with his or her job. The happier people are within their job, the more satisfied they are said to be. Job satisfaction is not the same as motivation, although it is clearly linked. Job design aims to enhance job satisfaction and performance; methods include job rotation, job enlargement and job enrichment. Other influences on satisfaction include the management style and culture, employee involvement, empowerment and autonomous work groups. Job satisfaction is a very important attribute which is frequently measured by organizations. It is interesting to find that some of the organizations, in spite of the overemphasis on the importance of human resources management in an organization, still pay less attention to the importance of job satisfaction. Due to lack of job satisfaction, most organizations either perform badly or lose skilled employees to other organizations with strong human resource policies. The organizations need to take note that "A happy employee is a happy customer."

(mba,2010). 


\subsection{Employee Commitment and Productivity}

In today's competitive business world, no organization can work at peak level unless all the employees are entirely committed to the organization. Working faithfully everyday independently is no more the primary requirement of the job. Employees nowadays have to be in shoes of entrepreneurs, working in teams proving their worth. Due to job switching and downsizing, employee loyalty has no denotation. This resulted in growing number of employees with feelings of broken promises on account of organizations. So in this type of situation, employee commitment is the best way out. Commitment can be defined as "a psychological state that binds the individual to the organization".(Allen and Meyer, 1990). Organization needs employees who are willing to go beyond the call of duty and engage in extra role behavior. This will not only increase the level of their commitment to the organization but also firm's productivity.

\subsection{Training and Productivity}

Companies today are forced to function in a world full of change and complexity, and it is more important than ever to have the right employees at the right job with the right qualification and experience in order to survive the surrounding competition. The successful and prosperous future of an organization is dependent on its skilled, knowledgeable and well experienced workforce. That is why training is a fundamental and effectual instrument in successful accomplishment of the firm's goals and objectives. Training not only improves them resourcefully, but also gives them a chance to learn their job virtually and perform it more competently hence increasing firm's productivity.

\subsection{Heterogeneity and Training}

Heterogeneity can be defined as fundamental characteristic of services which results in variation from one service to another or variation in the same service from day-to-day or customer-to-customer. Heterogeneity makes it hard for a firm to standardize the quality of its services. In case of training, unobserved heterogeneity creates a problem in efficiency of training. So it should be controlled to maximize the positive results.

\subsection{Endogeneity and Training}

"A parameter or variable is said to be endogenous, when there is a correlation between the parameter or variable and the error term. Endogeneity can arise as a result of measurement error, auotregression with autorelated errors, simultaneity, omitted variable, and sample selection error. (Wikipedia, 2010). In training it is related to the extraneous results of training i.e training does not achieve what it was meant for or it deviates from the desired results.

\subsection{Hypothesis}

- There is a positive impact of training on employee motivation, employee commitment and employee motivation.

- There is a positive impact of training on overall organizational productivity.

- There is a negative impact of unobserved heterogeneity and potential endogeneity on training effectiveness.

\section{Literature Review}

If we look into the literature available, there are hardly any studies addressing specifically the relationship between training effectiveness and job satisfaction, motivation and employee commitment under controlled heterogeneity and endogeneity, leading to productivity. Following researches have proved our hypothesis one way or the other.

- Motivation, is a subject deeply researched, in the organizational behavior literature, rich in perspectives, theories and models. From Maslow, to Alderfer, and Hertzberg to Hackman, growth is proposed to be one of the most effective motivators, resulting in higher efforts by employees. Furthermore, many researches revealed that motivation has an absolute link with job satisfaction and employee commitment in an organization. (Basset-Jones and Lloyd, 2005; Chen et al., 2004; Lok and Crawford, 2004).

- Sirota et al. (2005), in an important study on motivation and job satisfaction, involving 135,000 respondents from various countries and groupings, institute that organizations employing motivation schemes, tend to be far more effective than those organizations that do not. 
- Another researcher, Jeffrey Pfeffer (1998), also, presents two studies, representing the link between employee commitment and organizational performance. His studies established a positive relation between the use of commitment-oriented management practices and productivity.

- Training practices used by organizations may have an effect, direct or indirect on both employee motivation and organizational commitment (Meyer and Allen, 1991).

- In today's business world, employee's skills which are necessary to do their job are only possible through training. Most of the companies train their employees in such a manner that would help them to sustain throughout their careers. This kind of training can lead to high levels of motivation and commitment by the employees, who actually see the opportunity they are given. Training is defined in this study "as the planned intervention that is designed to enhance the determinants of individual job performance" (Chiaburu and Tekleab, 2005, p. 29).

- Training is related to the skills deemed necessary by the management of an organization that must be acquired by the members of that organization, in order to improve the probability of achievement of its goals. Training offered to employees, may help them reduce their anxiety or frustration, brought on by work demands, that they are not familiar with, and they are lacking the skills to handle effectively (Chen et al., 2004). Although there has been no direct link in the literature between training and job satisfaction, Rowden (2002) and Rowden and Conine (2005), propose that training may be used as a tool to increase job satisfaction.

- Rowden and Conine (2005), furthermore argues that trained employees will better satisfy the needs of their customers.

- Tsai et al. (2007), found that employees committed to learning showed a higher level of job satisfaction with a positive effect on their performance. Job satisfaction has been defined as "pleasurable or positive emotional state resulting from an appraisal of one's job or job experiences" (Locke, 1976, p. 1300).

- Training has been an important variable in increasing organizational productivity. Most of researches including Colombo and Stanca (2008), Sepulveda (2005) and Konings and Vanormelingen (2009) showed that training is a fundamental and effectual instrument in successful accomplishment of the firm's goals and objectives, resulting in higher productivity. But there is one important thing which is to be taken into account, training leads to productivity if the unobserved heterogeneity and potential endogeniety is controlled.

\section{The Proposed Model}

\section{Figure (1)}

The model in Figure (1) shows the impact of job training on job satisfaction, employee motivation and employee commitment, which leads to better level of productivity. By reviewing the literature we can propose and construct a model on how the corporate behavior can be improved by training. An employee in an organization is required to be effective and productive. In corporate sector, employee behavior is administered by his level of motivation, commitment and satisfaction. The more an employee has all three attributes, the better chance an employer has that his employee will perform well.

\subsection{Corporate Behavior before Training}

Employee needs training to overcome their shortcomings of skills and knowledge. They have to overcome this deficiency in order to be motivated and satisfied with their job. Motivated and satisfied employees are the one's which are more committed to the organization as well. So when the employees are not trained they feel like left alone by the organization, which leads to dissatisfaction, proceeding to higher turnover.

\subsection{Corporate Behavior after Training}

Trainings enhance the employee skills, knowledge and experience which is essential in today's rapidly changing workplace. In order for the organization to remain competitive and to retain its reputation for excellence, employees should have up-to-the-minute information and the ability to use new technologies, adapt to organizational change, work in flatter organizations in which cross-functional skills and knowledge are required, and work effectively in teams and other collaborative situations. Employees, too, recognize that it is essential for them to continue to get trained so that they will be effective in their current jobs and able to move into other positions or accept new responsibilities as circumstances demand. So by the help of training an employee knows his/her job well, leading to higher level of interest in the job. This will result in motivated employees who are 
satisfied with their jobs and are committed to the organizations, boosting the organizational productivity to optimal level.

\subsection{Corporate Behavior, Training and Controlled Variables}

Training is important part of corporate behavior. It not only enhances the behavior, but also molds it according to the expectations. In all the training process, the required results will only be achieved if unobserved heterogeneity and potential endogeneity are controlled. Otherwise no matter how effective trainings will be, the expected results will not be achieved.

\section{Conclusion}

This paper substantiates the strong relationship between employee training effectiveness and motivation, job satisfaction and commitment, resulting in increase in organizational productivity. The magnitude of the correlations from past researches indicate that the concepts examined are inextricably related and that this relationship, ought to be taken seriously by practicing managers, as well as academics. Future studies can further elucidate the found relationships, offering greater insight, concerning causality, incorporating more parameters in more comprehensive models and improving the efficaciousness of the existing ones.

\section{Discussion}

In accordance with the hypothesis, we can conclude the following results

- There is a positive relationship between of training and employee motivation, employee commitment and employee satisfaction. Whenever employees are trained, they are more motivated, committed and satisfied. The main reason is that when employee feels that he has been growing in an organization, his knowledge is not obsolete and he has been given importance in an organization and taken as an asset, he feels much more secure and starts owning the organization. This leads to motivated employees who work for long term growth of the organization, overall reduction in job switching and turnover and higher productivity due to employee satisfaction.

- There has been strong positive impact of training on overall firm's productivity. When employees are more motivated, committed and satisfied, they tend to be more skilled, knowledgeable, dedicated and well experienced. This directs to an overall organization culture where employees are focused, thoughtful, considerate and selfless working as one unit to achieve organizational goals, increasing employees productivity.

- If unobserved heterogeneity and potential endogeneity are controlled during training, its results are more precise. Training is not general nowadays; it is focused on specific skills which are to be developed in employees. But it is not necessary that what is planned to be achieved from training results in desired skill development. So if the training content is more focused and reliable, it leads to desired skill development in employees leading to higher job-knowledge fit, paving way for maximum resource utilization and productivity.

\section{Limitations}

The limitations faced by me over completion of research were minor yet proved to be intimidating at times

- I was not able to find any other research on the same subject, which caused lack of available literature on this subject.

- There may be other determinants of productivity which are not focused in my research.

- Due to time constraints, the generalizability of results can be challenged.

\section{Recommendation}

- The results of this study point to the fact that, equally important with the actual quality and "frequency" of the training programs offered to employees, is the perceived effectiveness of the training programs.

- Training perceived by the employees to be effective, will likely have a positive impact on job satisfaction, commitment and motivation.

- Looking at the results from the opposite angle, motivated, committed and satisfied employees will probably be more inclined to desire to learn more through training programs, adding thus value to the human capital of the organization.

- Although motivation, job satisfaction and commitment, went through the scrutiny of researchers for more than 50 years, training has not been studied for that long, so managers ought to be careful as to 
what constitutes "adequate" training and what the characteristics of effective training are, particularly in the eyes of the trainee.

- Other determinants of productivity should also be researched for future studies to get more accurate results.

- Organizations should emphasize on effectiveness of training as well instead of just emphasizing on training programs.

\section{References}

Allen, N. J., and Meyer, J. P. (1990). The Measurement and Antecedents of Affectice, Continuance and Normative Commitment to the Organization. Journal of Organizational Psychology, 63, 1-18.

Basset-Jones, N., and Lloyd, G.F. (2005). Does Herzberg's motivation theory have staying power?”. The Journal of Management Development, Vol. 24, pp. 929-43

Chen, T.Y., Chang, P.L., and Yeh, C.W. (2004). A study of career needs, career development programs, job satisfaction and the turnover intensity of R \& D personnel. Career Development International, Vol. 9 No. 4, pp. 424-37.

Chiaburu, D.S., and Tekleab, A.G. (2005). Individual and contextual influences on multiple dimensions of training effectiveness. Journal of European Industrial Training, Vol. 29 No. 8, pp. 604-26.

Colombo, Emilio \& Stanca, Luca. (2008). The Impact of Training on Productivity: Evidence from a Large Panel of Firms, Available at SSRN

Ezinearticles. (2010). [Online] Available: http://ezinearticles.com/? Employee-Motivation- And-Productivity --How-You-Motivate-Others-To-Do-As-Little-As-Possible\&id=691198 (Monday, 25 January, 2010)

Incentivequotes. (2010). [Online] Available: http://www.incentivequotes.com/employee-motivation.html (Wednesday, 27 January, 2010)

Konings, Jozef \& Vanormelingen, Stijn. (2009). The Impact of Training on Productivity and Wages: Firm Level Evidence, Discussion paper No. 244, Available at SSRN.

Lok, P., and Crawford, J. (2004). The effect of organisational culture and leadership style on job satisfaction and organisational commitment: a cross-national comparison. Journal of Management Development, Vol. 23 No. 4, pp. 321-38.

Locke, E. (1976). "The nature and the causes of job satisfaction", in Dunnette, M. (Ed.), Handbook of Industrial and Organizational Psychology, Rand-McNally, Chicago, IL, pp. 1297-349.

Mba. (2010). [Online] Available: http://www.mba.co.za/article.aspx?rootid=6\&subdirectoryid=1631 (Monday, 25 January, 2010)

Pfeffer, J. (1998). The Human Equation: Building Profits by Putting People First. Harvard Business School Press, Boston, MA.

Rowden, R.W. (2002). The relationship between workplace learning and job satisfaction in small and mid-sized businesses. Human Resource Development Quarterly, Vol. 13, pp. 407-26.

Rowden, R.W., and Conine, C.T. Jr. (2005). The impact of workplace learning and job satisfaction in small US commercial banks. Journal of workplace Learning, Vol. 17 No. 4, pp. 215-30.

Sepulveda, Facundo. (2005). Training and Productivity: Evidence for US Manufacturing Industries, Available at SSRN.

Sirota, D., Mischkind, L., and Meltzer, M.I. (2005). The Enthusiastic Employee: How Companies Profit by Giving Workers What They Want, Wharton School Publishing, Upper Saddle River, NJ.

Tsai, P., Yen, C.Y., Huang, L., and Huang, I. (2007). A study on motivating employee's learning commitment in the post-downsizing era: job satisfaction perspective. Journal of World Business, Vol. 42 No. 2, pp. 157-69.

Wikipedia. (2010). [Online] Available: http://en.wikipedia.org/wiki/Endogeneity (Monday, 25 January, 2010)

Wikipedia. [Online] Available: http://en.wikipedia.org/wiki/Heterogeneity (Monday, 25 January, 2010) 


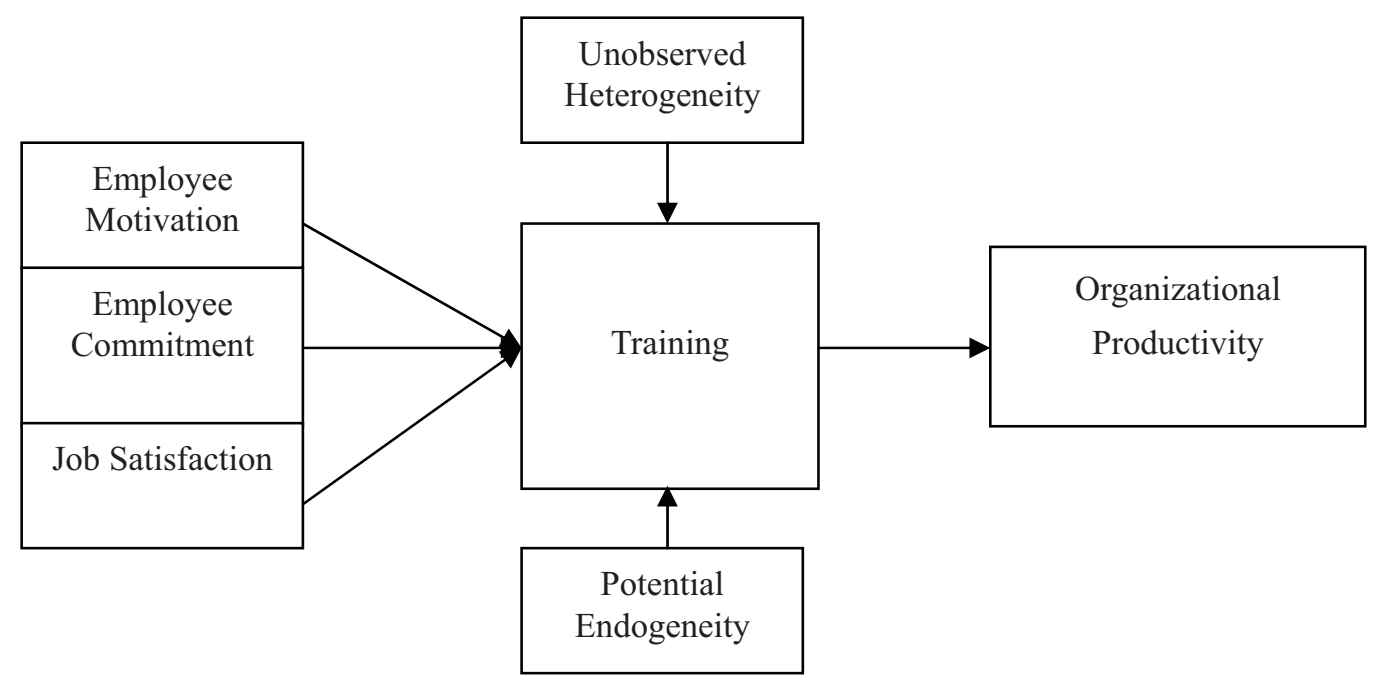

Figure 1. The Proposed Model 